Sharif University of Technology
Scientia Iranica
SCIENTIA
I RAN ICA

\title{
Simulation optimization of water-alternating-gas process under operational constraints: A case study in the Persian Gulf
}

\author{
S. Sadeghnejad ${ }^{\mathrm{a}, *}$, M. Manteghian, and H. Rouzsaz \\ Department of Petroleum Engineering, Faculty of Chemical Engineering, Tarbiat Modares University, Tehran, Iran. \\ Received 30 August 2018; received in revised form 13 December 2018; accepted 25 June 2019
}

\author{
KEYWORDS \\ Water-Alternating- \\ Gas (WAG); \\ EOR; \\ Optimization; \\ Simulated annealing; \\ Operational \\ constraints.
}

\begin{abstract}
The optimization of the efficiency of Water Alternating Gas (WAG) flooding projects can guarantee the success of these projects. Many operational constraints can indirectly affect flooding efficiency. Their effects are not normally considered during routine optimizations. The main aim of this study is to determine the influence of these constraints (e.g., maximum water-cut, maximum Gas-Oil Ratio (GOR), and minimum Bottom Hole Pressure (BHP) during the WAG process). Implementing a reservoir simulator coupled with Simulating-Annealing (SA) enables us to discover the effects of these constraints during simulation optimization. The developed optimizer is applied to a case study from an Iranian formation located in the Persian Gulf. The recovery factor of WAG flooding is compared with that of the conventional waterflooding and gas injection. Moreover, the optimization of individual and simultaneous WAG parameters is analyzed. Results indicate that: (a) Operational constraints can not only alter the production mechanism but also directly affect the ultimate recovery factor; (b) The recovery factor of simultaneous optimization of all WAG parameters is higher than that of individual parameter optimization; (c) Irrespective of the approach to parameter optimization, WAG ratio (or the volume fraction of injected water to gas) remains almost constant during all optimizations, showing the influence of this parameter during WAG flooding scenarios.
\end{abstract}

(C) 2019 Sharif University of Technology. All rights reserved.

\section{Introduction}

Waterflooding and gas injection are well-established techniques for production enhancement. However, due to the mobility ratio of both injection phases, the fingering effect is a common problem during flooding that can affect the recovery factor. Different methods have been introduced to reduce the drawbacks of these

\footnotetext{
*. Corresponding author.

E-mail address: sadeghnejad@modares.ac.ir (S. Sadeghnejad)
}

doi: $10.24200 /$ sci. 2019.51680 .2311 methods [1-5]. In order to make use of the benefit of the simultaneous injection of both fluids, WAG flooding was introduced $[6,7]$. In this method, by stabilizing the injection front, the remaining oil saturation of the formation decreases. In addition, gas injection reduces the oil saturation in bigger pores, whereas water flooding reduces the oil saturation in smaller pores [8]. Thus, WAG flooding can squeeze more volume of hydrocarbon out of a reservoir by combining factors including better mobility control, sweeping un-swept zones (i.e., macroscopic displacement), and improved microscopic displacement efficiency $[9,10]$.

WAG can be flooded in both miscible and immiscible approaches. It is notable that $79 \%$ of the WAG 
projects are miscible, highlighting the popularity of this approach [9]. Among miscible flooding processes, $\mathrm{CO}_{2}$-water-alternating injection has greater popularity nowadays $[11,12]$. The most important criterion for miscibility determination is the Minimum Miscibility Pressure (MMP). If a reservoir pressure reaches MMP, $\mathrm{CO}_{2}$ flooding is miscible. $\mathrm{CO}_{2}$-water-alternating injection can effectively enlarge swept volume and oil displacement efficiency [13]. The injection of $\mathrm{CO}_{2}$ into oil reservoirs has two advantages: increasing oil production and sequestering $\mathrm{CO}_{2}$ as an environmental measure [14]. Yan et al. studied the displacement process and exquisite interaction mechanism on a pore scale by analyzing the adsorbed oil layer during $\mathrm{CO}_{2-}$ WAG injection [15]. Liu and Zhang simulated the injection of $\mathrm{CO}_{2}-\mathrm{CH}_{4}$ mixtures [16]. They showed that the rhythmic injection of these fluids could offer a better mobility ratio and delay water breakthrough.

There are very good case studies for the application of optimization algorithms in the petroleum literature [17-20]. However, the related studies of finding the optimal conditions in WAG processes are restricted to parameter sensitivity analysis via nonsystematic approaches. In these studies, a limited quantity of simulation runs (i.e., without implementing any optimization algorithm) were conducted to determine an optimum condition. For example, an integrated approach to reservoir modeling was used to evaluate the performance of the miscible WAG process in Alaska [21]. Bedrikovetsky et al. developed an analytical model for a tertiary miscible $\mathrm{CO}_{2}$-WAG [22]. A simulation study using full-field compositional reservoir modeling was undertaken to manually optimize (i.e., without implementing any optimizer) the design of miscible or immiscible $\mathrm{CO}_{2}$ water-alternating flood in a pilot located in Jilin oil field [23]. Ghomian et al. investigated the effect of hysteresis, WAG ratio, slug size, and heterogeneity on $\mathrm{CO}_{2}$-WAG flooding without the implementation of any optimization tool [24]. Furthermore, Alizadeh et al. (2014) conducted a series of numerical sensitivity studies to determine the magnitude of scaling groups and their interaction with recovery factors during immiscible WAG displacement processes [25]. Liu et al. (2016) investigated the parameters influencing WAG for $\mathrm{CO}_{2}$ flooding by only using a numerical simulation package in a low permeability block of Jilin oil field [26]. Chen et al. developed a multi-level programming model from a life-cycle perspective for implementing the shale gas supply chain system. A set of leader-followerinteractive objectives with emphasis on environmental, economic, and energy concerns was incorporated into the synergistic optimization process [27]. Moreover, an inexact multi-criteria decision-making model with consideration of shale gas production profiles and recoverable reserves was analyzed in detail [28].
It is crucial to optimize operational parameters based on the overall economy (e.g., net present value, overall project economy, and oil recovery) in WAG projects [29]. There are some studies in the WAG literature that have implemented optimization and artificial intelligence algorithms in their applications during WAG flooding, but without emphasizing the role of production mechanisms imposed by production constraints. For example, Yang et al. implemented simulated annealing and genetic algorithm and analyzed the capability of these techniques in WAG process optimization [30]. Moreover, a 3D reservoir simulator integrated with an EOR expert system was used to determine the reservoir strategies to optimize the oil recovery from a carbonate reservoir with WAG techniques [31]. Esmaiel and Heeremans introduced a response surface proxy model using optimal design through decision-making during WAG flooding in order to reduce the number of required simulation runs [32]. Ma (2010) used a commercial simulator and a neural network toolbox to build an artificial neural network model for screening and designing WAG processes [33]. Odi and Gupta simulated a $\mathrm{CO}_{2}$-WAG core flood results by applying non-adjoint-based optimization algorithms to find an optimal WAG configuration [34]. In 2013, a heuristic simplex algorithm was used to find the maximum NPV and the best injection scenario in the mixed-integer nonlinear problem optimization during WAG processes [35]. Moreover, Mohagheghian utilized different evolutionary algorithms to optimize hydrocarbon WAG performance in a real case study [36]. He tested the optimization tools with different controlling variables (e.g., injection rates, cycle ratio, time, etc.) to compare the performance, convergence speed, and the quality of the optimal solutions found by those algorithms. The previous studies paid insignificant attention to the role of operational constraints during the optimization of WAG scenarios. These parameters, as operative limitations, would alter the production mechanism of a field. Thus, ignoring them during flooding scenarios might result in the misleading of optimization results.

The factors that can affect the success of WAG projects can be categorized into two groups: reservoir parameters (e.g., heterogeneity, petrophysical properties, and fluid properties) and operational parameters (e.g., injection pattern, injection rate, WAG cycle, cycle time, etc.) [36]. The focus of this study is on the optimization of the later parameters. As a case study, the dataset of an Iranian offshore heavy oil formation located in the Persian Gulf was nominated. By coupling a reservoir simulator with a Simulated Annealing (SA) optimization algorithm, different production/injection scenarios are investigated. In our simulation-optimization approach, we have considered some injection/production parameters as variables and 
the ultimate oil recovery as an objective function. The main objective of this research is to reveal the role of operational constraints during optimization and evaluate their effects on the optimization results. Subsequent to the natural production period of the field, the injection rates of water and gas flooding are optimized. Afterward, the optimizations of the WAG flooding parameters (e.g., injection rates, WAG ratio, and cycle time) are considered in detail. The ultimate recovery factors of the individual and simultaneous optimization of these parameters are compared together. During all simulation optimization scenarios, the effect of operational constraints on finding the optimal scenario with the maximum recovery factor is discussed in detail.

\section{Material and methods}

\subsection{Statement of the problem}

Simulation can be considered as an effective tool to analyze the details of a production process [37] and predictions of its future behavior. In petroleum engineering, production optimization plays an important role in increasing the amount of produced hydrocarbon and increasing its recovery factor. Optimization is one of the best ways to find a proper solution without the need to investigate all possible statuses during simulations [38]. The purpose of this study is to investigate the role of operational constraints in the ultimate oil recovery of a WAG flooding project during the production optimization process.

Because of either facility limitations (both downhole and surface) or economic issues, many restrictions should be considered during a simulation-optimization scenario. For example, during the simulations, each well can operate at a specific target value, including oil/water/gas flow rate or bottom-hole/tubing-head pressure. Changing the control mode of a well from a primary mode to other modes is a routine to meet the operational constraints. For example, due to reservoir pressure reduction, the well may not produce more hydrocarbons at the initial rate with a BHP above the minimum BHP-limit set by the user. Therefore, the producing well with an oil-flow-rate target may be converted to a fixed BHP mode. The well control mode is then changed automatically to maintain a constant $\mathrm{BHP}$, wherein the oil production rate will decline. This process can be reversed when the oil production of this well exceeds the oil-rate target by any reason, e.g., well stimulation, secondary recovery, or EOR scenarios. Furthermore, drilling the best location of injection and producing wells is a challenging task that can affect the reservoir connectivity between wells [39-44]. In addition, a well or its connections might automatically be closed due to the violation of some other economic constraints. For example, the surface facility of a well is designed to work under a specific gas (or water)to-oil ratio limit (i.e., an operational limit), and it cannot process excess gas (or water). Examples of such economic well constraints include lower economical limit for hydrocarbon production rate, maximum water cut (or water-hydrocarbon ratio), and maximum Gas-Oil-Ratio (GOR). Overlooking the aforementioned constraints during any EOR optimization definitely alters the final results. Therefore, the operational constraints should be considered for the proposed case studies. These targets can be considered via constrained optimization approaches.

In order to investigate the role of operational constraints in this study, different scenarios are considered and the results are compared together (Figure 1). In the first scenario, natural production from the field under study is discussed as a base case. The objective of this scenario is to find an optimum production rate with the ultimate maximum recovery, considering the operational constraints. In the second and third scenarios, the optimum injection rates during waterflooding and gas injection into the field are investigated. The injection in these scenarios starts with a lag of 28 years after the natural production

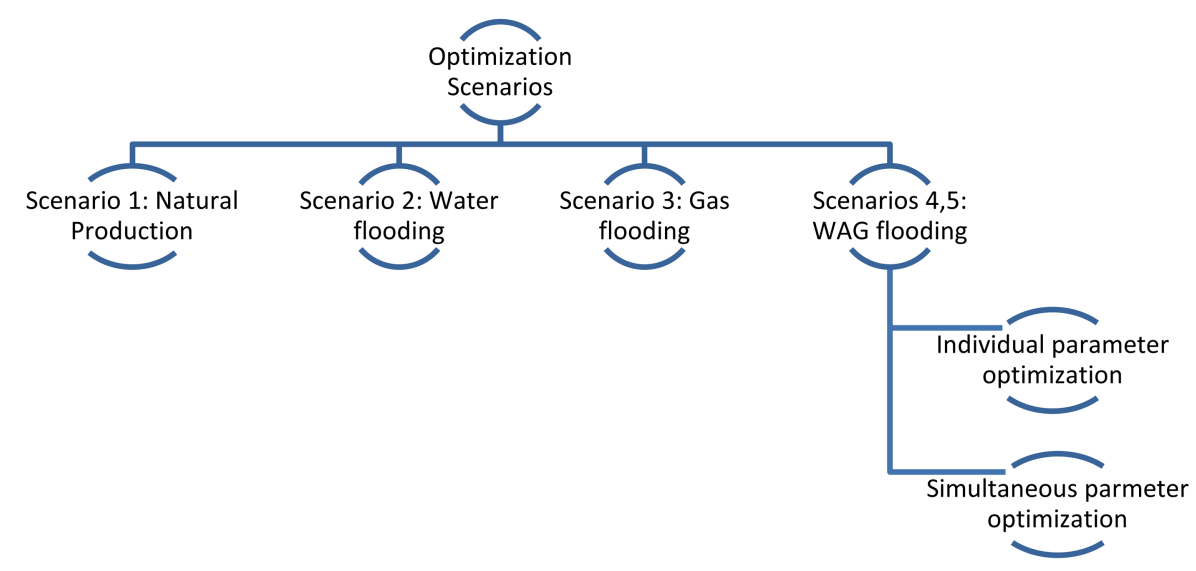

Figure 1. Scenarios considered during simulation optimization. 
period. Furthermore, the optimization of injection cycle time, injection ratios, and water/gas injection rates during WAG flooding are examined. These parameters are individually optimized and, during each optimization scenario, the optimized values from the previous results are implemented. At the final stage, the simultaneous optimization of all parameters is performed, and its results are compared with individual parameter optimizations.

\subsection{Goal and scope}

The primary goals of this study can be summarized as follows:

(a) Coupling a simulated annealing simulator with a black oil simulator to find the best production scenario;

(b) Finding the best injection-production scenario during natural production, waterflooding, gas injection, and WAG flooding in the case under study;

(c) Investigating the role of operational constraints in the production optimization of the defined simulation scenarios;

(d) Investigating the role of individual and simultaneous optimization of WAG parameters during the ultimate recovery.

These goals can be achieved by:

(a) Finding the effect of the following operational constraints: lower economical-limit for the hydrocarbon production rate, maximum water cut (or water-hydrocarbon ratio), and maximum GOR;

(b) Finding the optimum production rate, water injection rate, and gas injection rate during natural production, waterflooding, and gas injection scenarios, respectively;

(c) Finding optimum water and gas cycle time, water injection rate, and gas injection rate during WAG flooding scenarios.

\subsection{Simulated Annealing (SA) optimizer}

Optimization algorithms offer a potential for a systematic investigation of a broader set of production scenarios under a given condition. These algorithms together with the experienced-judgment of specialists allow for a better assessment of formation uncertainty and significantly reduce possible risks in decisionmaking. Consequently, there is an increasing interest in the implementation of optimization algorithms in the oil industry. However, the selection of an appropriate optimization algorithm, runtime configuration, and the dynamic optimization of a reservoir remain a challenging problem [45].

In this study, the SA optimization algorithm is selected as an efficient optimization method. This optimization algorithm is implemented in the petroleum literature for many different applications [46-49]. SA was first introduced by Kirkpatrick et al. [50] and Cerny [51]. This method is motivated by an analogy to solid annealing and is classified as a heuristic method [52]. In order to apply the SA method to a specific problem, different parameters should be specified including cost function (i.e., objective function), random neighboring solution, acceptance probability function, and annealing schedule temperature (i.e., cooling schedule). The details of this algorithm and the parameters used in our specific simulation-optimization approach are mentioned in Appendix A.

\subsection{Simulation assumption}

The key assumption during simulations includes:

- Three-dimension three-phase simulation is performed on the field scale;

- The black oil fluid model is considered in which the oil and gas properties may change with time and pressure, but their composition is constant;

- The fluid model is considered to be slightly compressible in which fluid compressibility is constant in a certain range of pressures;

- Corner-point gridding based on the notion of coordinate lines and corner depths with non-uniform grids is used during simulations;

- A heterogeneous rock model is considered, in which each grid cell has its own porosity and permeability;

- A five-point stencil scheme is used for discretizing the simulation partial differential equations;

- Reversible rock compressibility is considered elsewhere.

An E100 package was used as the simulator of this study. The input data file was written based on the data from one of the Iranian formations.

\subsection{Coupled simulation optimization approach}

To determine an optimum solution, a simulator should be coupled with an optimizer. Figure 2 illustrates the communications between the implemented simulator and the optimizer. The optimizer package and the related input/output programs are coded in Matlab. The protocol concerning these communications between the optimizer and the simulator was made by reading/writing on ASCII files.

The algorithm starts with the definition of input parameters for both optimizer and simulator. The optimizer parameters include initial temperature, cooling schedule, equilibrium condition, and final termination condition. The simulator parameters consist of the number of injection and production wells, decision variables, and well constraints. Appendix A discusses the details of the SA approach. 


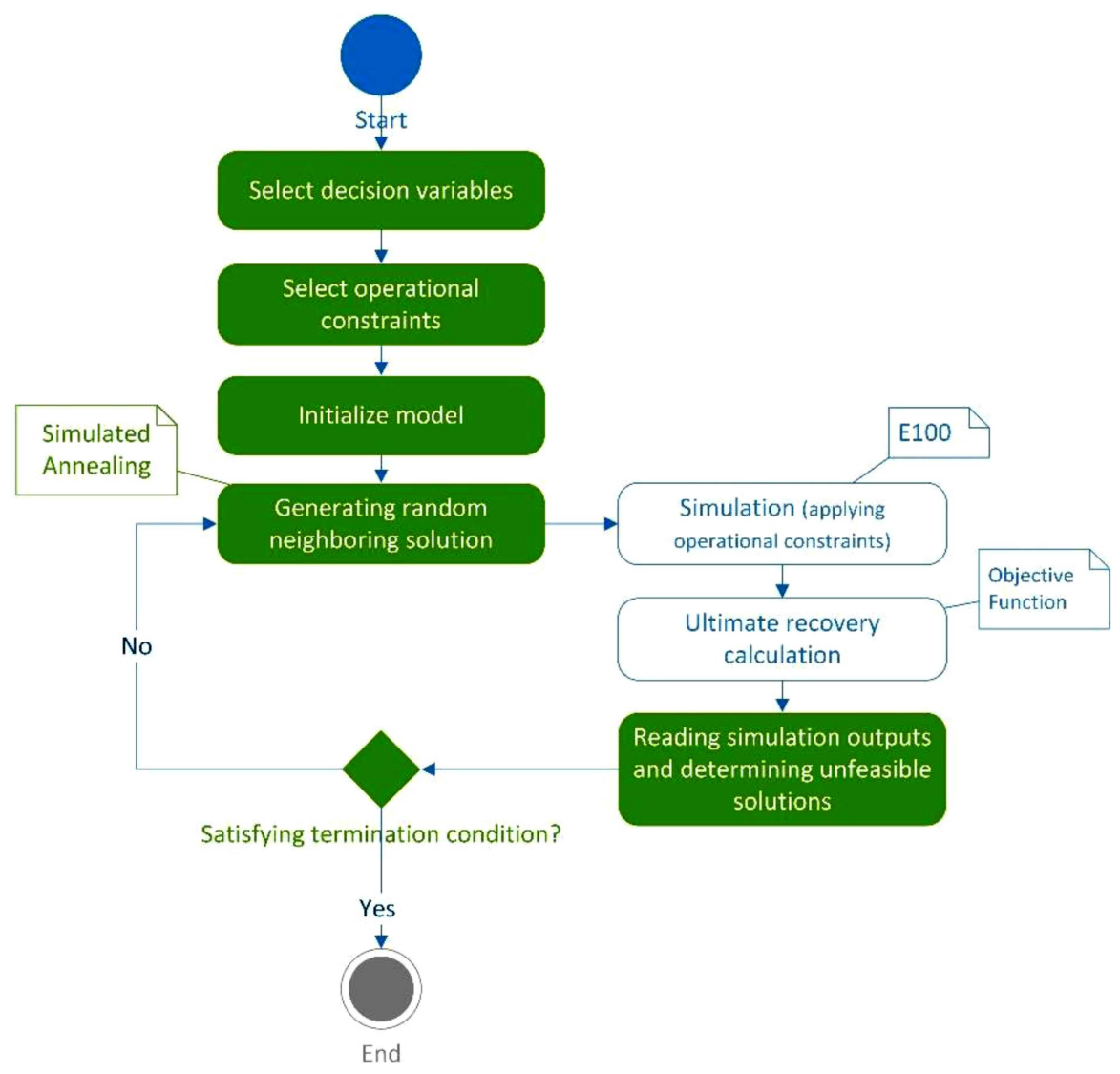

Figure 2. Schematic illustration of the coupled simulator-optimizer algorithm. The optimization and simulation sections are shown with filled green and blue boxes, respectively.

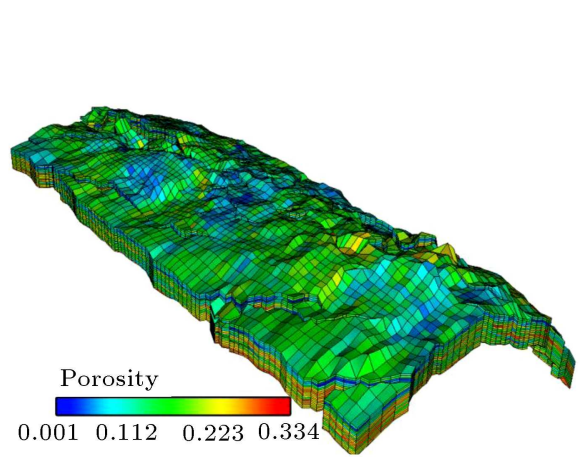

(a)

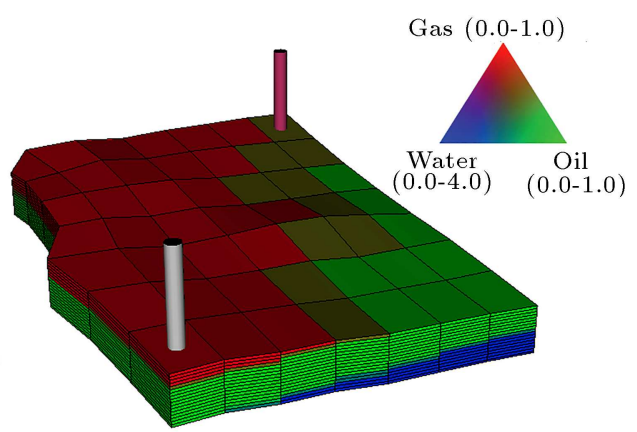

(b)

Figure 3. (a) Porosity map of the formation under study. (b) Selected sector of the field showing the initial saturation of the reservoir for three available phases (i.e., oil, water, and gas).

During the optimization of each scenario, the SA optimizer is responsible for generating random neighbor solutions and requesting the simulator to evaluate the objective function value (i.e., ultimate recovery factor). The simulator tries to compute the ultimate recovery of the field at a fixed time after the start of the production (e.g., 50 years) by applying the operational constraints. The optimizer calls the simulator for so many times to reach an optimum condition in each scenario.

\subsection{Case study}

As a case study, an Iranian offshore oil reservoir has been used (Figure 3(a)). A sector is selected through the entire reservoir with $7 \times 7 \times 20$ blocks (the total number of blocks is 980). The dimensions of the blocks in the $x$-, $y$-, and $z$-directions are 128,177 , and $3.5 \mathrm{~m}$, respectively. The reservoir under study has an initial pressure of $19.3 \mathrm{MPa}$ and contains $680,599 \mathrm{~m}^{3}$ of oil originally in place. Two wells on either side of the model were considered (Figure $3(\mathrm{~b})$ ). During the 
Table 1. Rock and fluid properties of the reservoir under study.

\begin{tabular}{lclc}
\hline \multicolumn{1}{c}{ Property } & Amount & \multicolumn{1}{c}{ Property } & Amount \\
\hline Porosity $(\%)$ & $3-32$ & Oil density $\left(\mathrm{kg} / \mathrm{m}^{3}\right)$ & 935.96 \\
Horizontal permeability $\left(\times 10^{-11} \mathrm{~m}^{2}\right)$ & $0-1.35$ & Gas density $\left(\mathrm{kg} / \mathrm{m}^{3}\right)$ & 1.3 \\
Vertical permeability $\left(\times 10^{-11} \mathrm{~m}^{2}\right)$ & $0-0.13$ & Water density $\left(\mathrm{kg} / \mathrm{m}^{3}\right)$ & 1140.03 \\
Rock compressibility $(1 / \mathrm{Pa})$ & $8.7 \times 10^{-10}$ & Oil viscosity $(\mathrm{mPa} . \mathrm{s})$ & 3.65 \\
Bubble point pressure $(\mathrm{MPa})$ & 18.62 & Water viscosity $(\mathrm{mPa} . \mathrm{s})$ & 0.55 \\
Initial reservoir pressure $(\mathrm{MPa})$ & 19.31 & Gas viscosity $(\mathrm{mPa} . \mathrm{s})$ & 0.02 \\
\hline
\end{tabular}

natural production period, both wells were producing and, in the other scenarios, one of them was considered as an injector of water and/or gas. Table 1 summarizes the rock and fluid properties.

Figure 4 depicts the water-oil and gas-oil drainage relative permeability data of the formation. Since the intersection of the relative permeability curves of the water and oil phase is at a point lower than (but close to) a water saturation rate of $50 \%$, the reservoir rock is neutral-wet. During WAG flooding, three-phase flow conditions and, especially, hysteresis effects become relevant in the recovery process [53]. Hysteresis effects become larger in processes with fluid flow reversal as in the case of WAG injection. In order to consider this phenomenon, the hysteresis capability of the simulator based on the methodology of Aziz and Settari [54] was implemented during our simulations.

Table 2 summarizes the well production/injection parameters during all scenarios. In this study, the parameters such as maximum water-cut, maximum GOR, minimum BHP, and minimum oil flow rate were investigated as effective operational constraints. The values of these parameters were set based on the operational values of the field under study (i.e., field readings). The considered control modes and

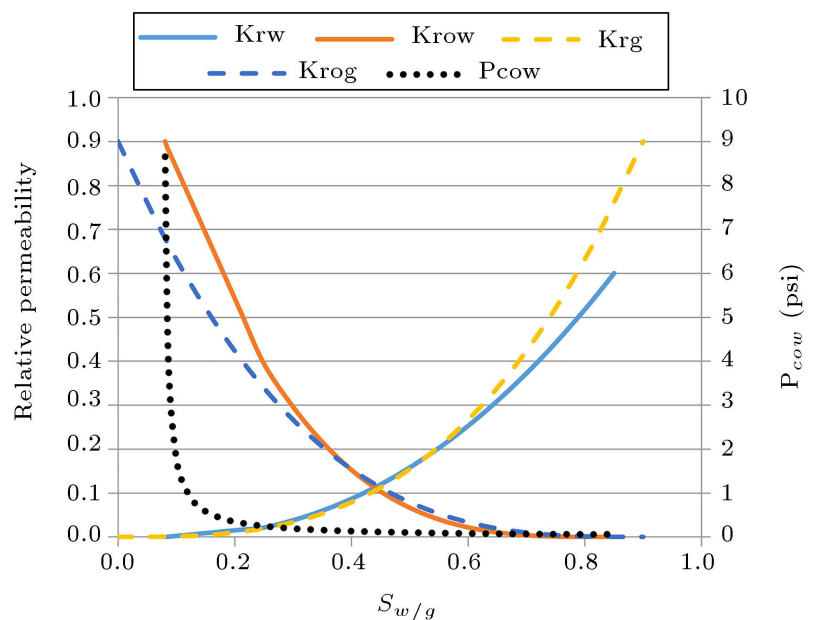

Figure 4. Relative permeability and capillary pressure data used during simulations.

well constraints during our simulation are shown in Table 3.

\section{Results and discussion}

\subsection{Optimizing natural production scenario}

The type of energy (i.e., production mechanism) available for moving hydrocarbon fluids to the production

Table 2. Production/injection parameters considered during the optimization of water flooding, gas injection, and WAG injection scenarios.

\begin{tabular}{lcccc}
\hline \multirow{2}{*}{ Well production/injection parameters } & \multirow{2}{*}{ Value } & \multicolumn{2}{c}{ Scenarios } \\
\cline { 3 - 5 } & & Water flooding & Gas injection & WAG \\
\hline Production rate $\left(\mathrm{m}^{3} / \mathrm{d}\right)$ & 238.48 & $\sqrt{ }$ & $\sqrt{ }$ \\
Maximum injection BHP $(\mathrm{MPa})$ & 20.68 & $\sqrt{ }$ & $\sqrt{ }$ \\
Water injection rate $\left(\mathrm{m}^{3} / \mathrm{d}\right)$ & 238.48 & - & - & $\sqrt{ }$ \\
Gas injection rate $\left(\mathrm{m}^{3} / \mathrm{d}\right)$ & 18,405 & - & - & $\sqrt{ }$ \\
\hline
\end{tabular}

Table 3. Well operational constraints in the field under study.

\begin{tabular}{lll}
\hline \multicolumn{1}{c}{ Well constraints } & limit & \multicolumn{1}{c}{ Description } \\
\hline Oil flow rate for each well $\left(\mathrm{m}^{3} / \mathrm{d}\right)$ & $<31.80$ & The well is closed if this limit is broken \\
Bottom hole pressure $(\mathrm{MPa})$ & $<6.20$ & Production changes from a constant rate mode to a constant BHP mode \\
Water cut $(\%)$ & $>50$ & The worst-offending connection in the well is closed \\
Gas-oil-ratio $\left(\mathrm{m}^{3} / \mathrm{m}^{3}\right)$ & $>356.2$ & The worst-offending connection in the well is closed \\
\hline
\end{tabular}




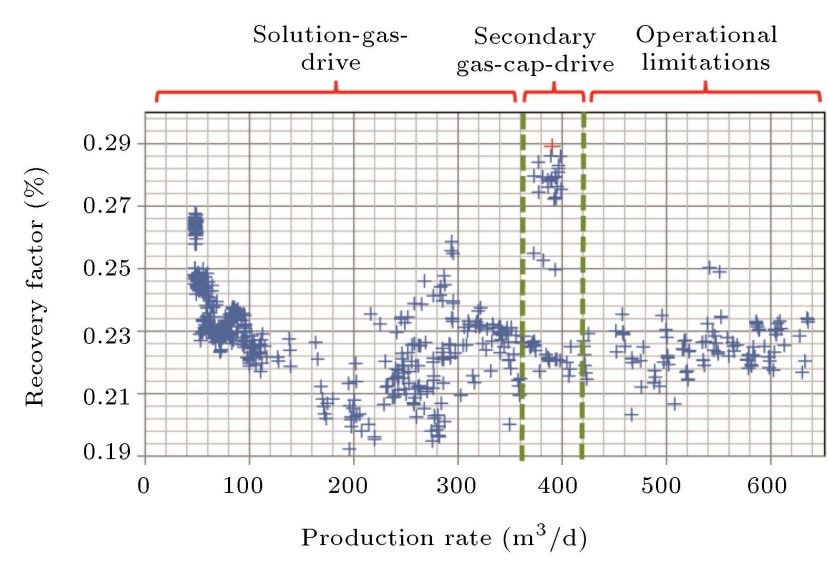

Figure 5. Production rate optimization of 652 simulations during natural production. The optimum rate $\left(390.63 \mathrm{~m}^{3} / \mathrm{d}\right)$ is shown with a red cross. The recovery factor of rates from 360 to $420 \mathrm{~m}^{3} / \mathrm{d}$ (distinguished by two dashed lines) behaves differently from the other regions.

wells is quite important for determining the amount of recovery factor during natural production [55]. Moreover, reservoirs are usually subjected to different production mechanisms that may change during their production lifetime. The primary production mechanisms of the reservoir under study are compaction-drive and solution-gas-drive mechanisms. Pressure depletion causes the gas phase to appear in the formation because of the release of dissolved gas once the pressure falls below the bubble point pressure. Gas releasing in the reservoir can have either positive or negative effects. The negative factors include the following: Either increasing the gas-oil-ratio in production wells may cause some operational problems or the reservoir pressure decreases more rapidly than the pressure drop of an under-saturated reservoir. Nevertheless, if the produced gas has sufficient time to develop a secondary gas cap in the formation, then the rate of pressure drop reduces as the gas cap expansion can compensate for the pressure drop rate of the formation (i.e., a positive factor).

Figure 5 displays the results of the applied optimization to evaluate the optimum production rate of the reservoir under study during natural production. Each point in this graph represents the result of a single simulation run, which was called by the SA optimization algorithm. The figure outlines the result of 652 simulations (i.e., function calls) with different production rates in the range of 48 to $636 \mathrm{~m}^{3} / \mathrm{d}$.

As the production rate increases, more gas is produced; in addition, a modest downward trend in recovery factor is observed in Figure 5. However, there is an unconventional rise in the recovery factor curve from 360 to $420 \mathrm{~m}^{3} / \mathrm{d}$ (distinguished by two dashed lines in Figure 5), in which the ultimate recovery reaches a peak of $28.9 \%$ at a rate of $390.63 \mathrm{~m}^{3} / \mathrm{d}$. The dominant production mechanism for the production

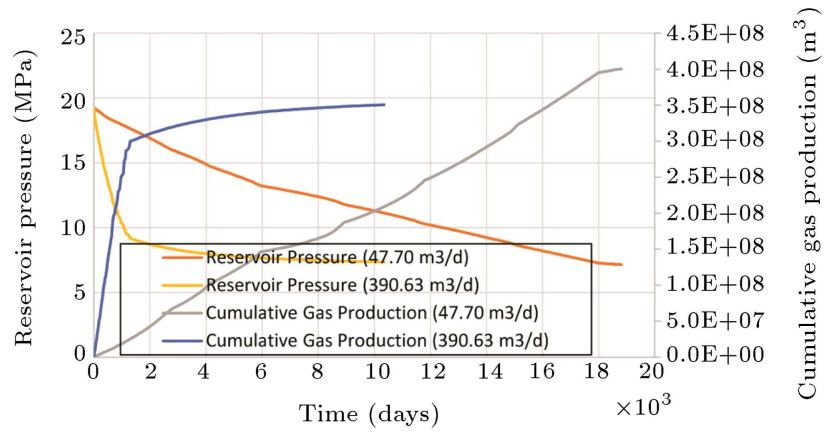

Figure 6. Comparison of average reservoir pressure and cumulative gas production of two different production scenarios with production rates of 47.70 and $390.63 \mathrm{~m}^{3} / \mathrm{d}$.

rates less than $360 \mathrm{~m}^{3} / \mathrm{d}$ is solution-gas-drive, whereas the production is limited by the field maximum GOR, caused by the surface facility limitations at rates over than $420 \mathrm{~m}^{3} / \mathrm{d}$. At the optimum production rate of our study (i.e., $390.63 \mathrm{~m}^{3} / \mathrm{d}$ ), the operational constraints helped the formation have a higher recovery factor. During the production, the upper perforations of the well were automatically closed due to high-production GOR (i.e., > $356.2 \mathrm{~m}^{3} / \mathrm{m}^{3}$ from Table 3 ); therefore, the lower perforations only continued to produce more hydrocarbon. The closure of the upper perforations resulted in ceasing gas production and, consequently, developing a secondary gas cap in the reservoir. Thus, the expansion of this gas cap can maintain the reservoir pressure as the dominant drive mechanism. In this situation, the recovery factor of the reservoir reaches its maximum value of $28.9 \%$.

To validate the creation of the secondary gas cap in the reservoir, Figure 6 shows the reservoir average pressure and cumulative gas production for production rates of 48 and $390 \mathrm{~m}^{3} / \mathrm{d}$. For the former production rate, the reservoir pressure falls steadily, while, for the later production rate, pressure dramatically slumps in primary steps $(t<1200$ days $)$ and moderately declines afterward. This sudden reduction in the pressure drop rate results from the release of the solution gas. After 1200 days, gas production rise continues, but with a rate more moderate than before. This is because of the closure of the upper perforations and the creation of the secondary gas cap that can displace oil below gas-oil-contact in a piston-like manner toward the open completions.

\subsection{Optimizing waterflooding scenario}

The aim of this scenario is to find the optimum waterinjection rate. During waterflooding, the production well produces at a rate of $238.48 \mathrm{~m}^{3} / \mathrm{d}$. The results of 659 simulations with different water injection rates are illustrated in Figure 7. The optimum injection rate is calculated to be $164.55 \mathrm{~m}^{3} / \mathrm{d}$ with a recovery factor of $35.5 \%$, which is almost $6.6 \%$ higher than the natural production. 


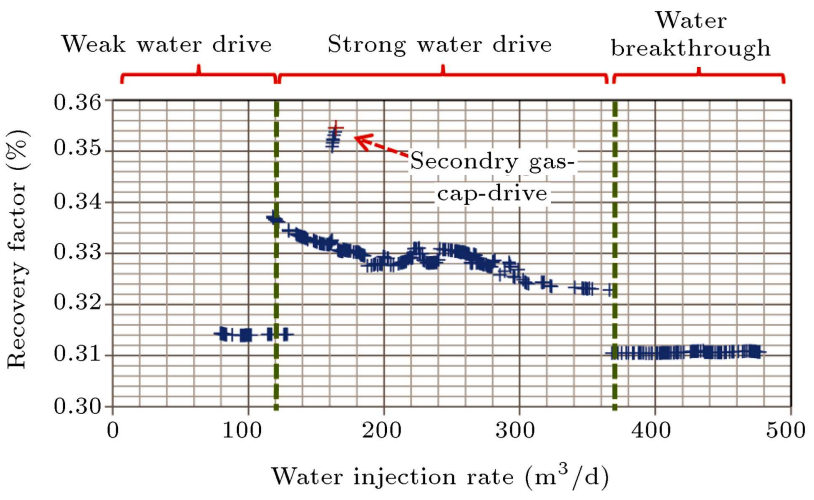

Figure 7. Optimization of the water injection rate in the water flooding scenario. The optimum injection rate $\left(164.55 \mathrm{~m}^{3} / \mathrm{d}\right)$ is shown with a red cross. The recovery factor behaves differently in the three defined injection rate ranges with the vertical dashed lines.

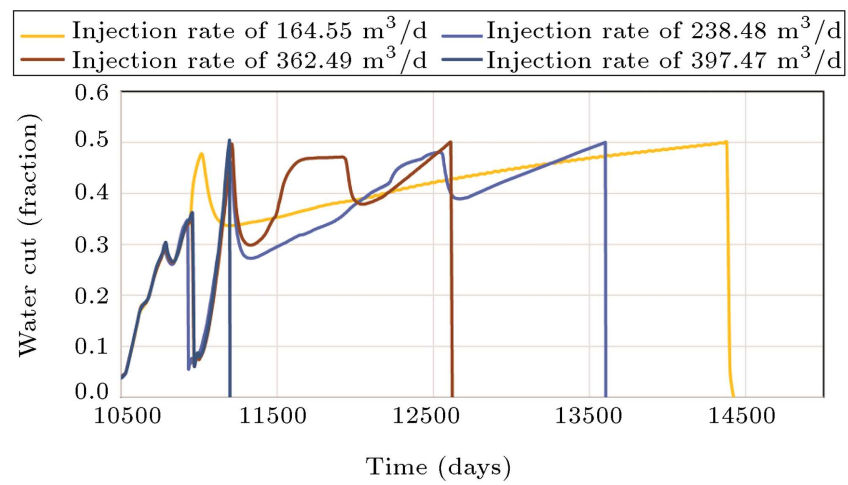

Figure 8. Comparison of production water cut at different injection rates of $164.55,238.48,362.49$, and $397.47 \mathrm{~m}^{3} / \mathrm{d}$. Injecting with higher rates decreases water breakthrough time.

At low injection rates $\left(q_{i n j}<120 \mathrm{~m}^{3} / \mathrm{d}\right)$, the injected water could not compensate the reservoir pressure drop due to the production (i.e., weak water-drive mechanism); therefore, the recovery factor remained almost constant irrespective of the water injection rate. On the contrary, water broke through at high injection rates $\left(q_{i n j}>370 \mathrm{~m}^{3} / \mathrm{d}\right)$. After the breakthrough of water in the production well, no more oil could be produced and the sweep efficiency remained almost constant irrespective of the injection rate, because the completions reached their maximum-water cut constraint in these cases (i.e., $50 \%$ in Table 3 ) and were closed. This behavior can easily be seen in Figure 8, where an increase in the injection rate (e.g., injection rate of 264.55 to $397 \mathrm{~m}^{3} / \mathrm{d}$ ) resulted in a dramatic rise in well water-cut in preliminary time steps. Thus, the well completions automatically were closed, and watercut plummeted to zero.

Furthermore, Figure 7 shows a declining trend of recovery factor from an injection rate of 120 to $370 \mathrm{~m}^{3} / \mathrm{d}$. This is because of the availability of a

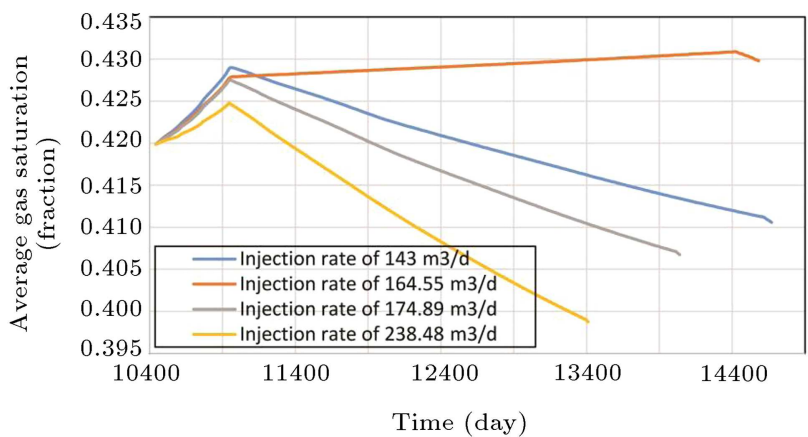

Figure 9. Average gas saturation of reservoir, $\bar{S}_{g}$, for different water flooding scenarios with an injection rate of $143,164.55,174.89$, and $238.48 \mathrm{~m}^{3} / \mathrm{d}$. The optimum injection rate, $164.55 \mathrm{~m}^{3} / \mathrm{d}$, behaves differently from the other scenarios.

balance between injection and production rates (i.e., strong water drive mechanism). This balance prolonged the breakthrough time and increased the pistonlike movement behavior of the injected fluid. However, a sharp jump in the recovery factor is observable in this figure around an injection rate of $164.55 \mathrm{~m}^{3} / \mathrm{d}$. Since this injection rate was lower than the production rate (i.e., $238.48 \mathrm{~m}^{3} / \mathrm{d}$ ), the injected water could not maintain the reservoir pressure and, finally, gas was released from the formation fluid (i.e., $P<P_{b}$ ). The expansion and migration of this gas to the formation gas-cap could support the reservoir pressure; therefore, the maximum recovery of $35.5 \%$ could be achieved.

Figure 9 depicts the average gas saturation, $\bar{S}_{g}$, of the reservoir at different injection rates. At all injection rates (except $164.55 \mathrm{~m}^{3} / \mathrm{d}$ ), as the injection rate increases, $\bar{S}_{g}$ falls because the injected water may support the pressure reduction. The $\bar{S}_{g}$ of the formation rose in the primary steps $(t<11000$ days $)$ and before gas breakthrough. After gas breakthrough, due to the formation depletion and gas production, $\bar{S}_{g}$ decreased. The trend of $\bar{S}_{g}$ at an injection rate of $164.55 \mathrm{~m}^{3} / \mathrm{d}$ is different from that in the other scenarios. At this rate, $\bar{S}_{g}$ of the reservoir went up over time. During waterflooding with this rate, the upper perforations quickly reached the maximum GOR constraints (i.e., in Table 3) and were automatically closed. In this situation, the released gas could not be produced. Increasing $\bar{S}_{g}$ resulted in the creation of a secondary gas cap in the reservoir and, consequently, a rise in recovery factor. Thus, $\bar{S}_{g}$ of the formation rocketed despite the trend of the other scenarios. Again, this phenomenon emphasizes that the operational constraints can influence the production results.

\subsection{Optimizing gas injection scenario}

Figure 10 depicts the result of 699 simulations during the SA optimization of gas injection rates. The optimum ultimate recovery $(39.1 \%)$ was obtained at a gas injection rate of $18,122 \mathrm{~m}^{3} / \mathrm{d}$, which was 10.2 


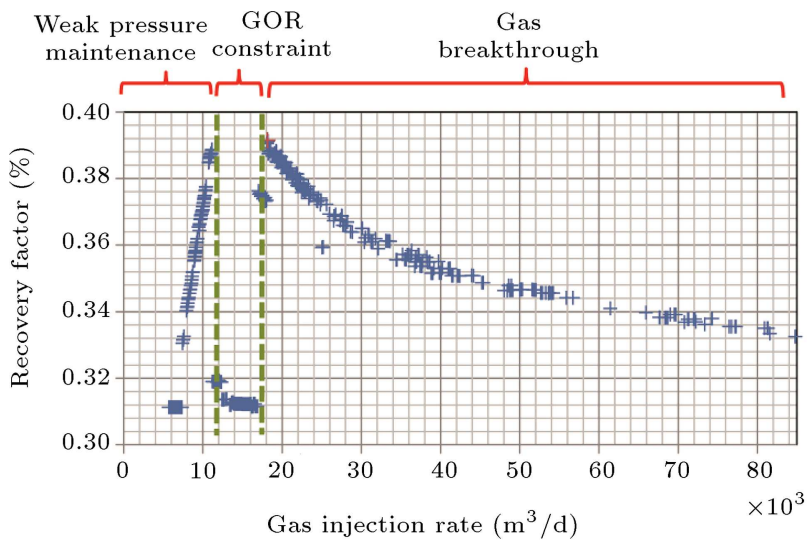

Figure 10. Recovery factor versus gas injection rate during optimization. The optimum gas injection rate $\left(18,122 \mathrm{~m}^{3} / \mathrm{d}\right)$ is shown with a red cross. Three different recovery factor behaviors can be seen (distinguished by two vertical dashed lines).

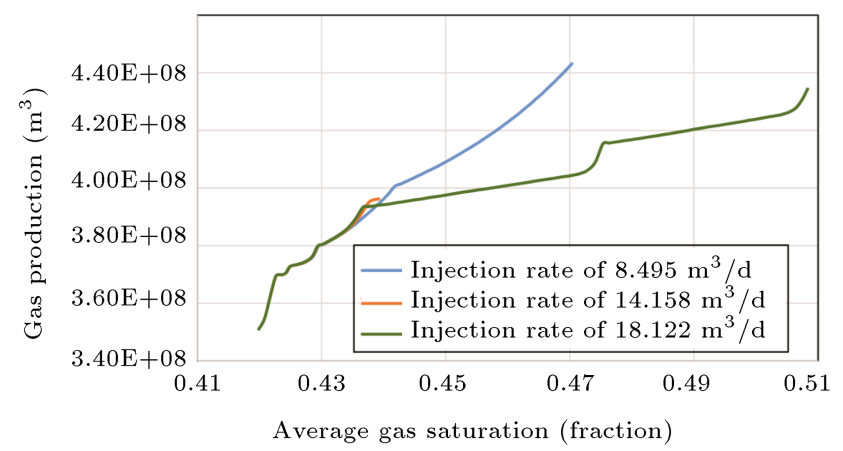

Figure 11. Field gas production for three different gas injection scenarios with injection rates of 8495,14158 , and $18122 \mathrm{~m}^{3} / \mathrm{d}$.

and $3.7 \%$ higher than the natural production and water flooding scenarios, respectively.

The trend of Figure 10 can be classified into three regions. The gas fingering effect and breakthrough continuously reduced the formation recovery factor at injection rates higher than $18,000 \mathrm{~m}^{3} / \mathrm{d}$. At higher injection rates, gas fingering reduced the injection sweep efficiency and the recovery factor, too. The recovery factor curve reached its highest point, $39.1 \%$, at a gas injection rate of $18,122 \mathrm{~m}^{3} / \mathrm{d}$. In addition, the recovery factor curve surged at low gas injection rates $\left(q_{i n j}<12,000 \mathrm{~m}^{3} / \mathrm{d}\right)$. The reason for this behavior is that, prior to gas breakthrough, higher gas injection rates could compensate for more reservoir pressure drop due to the production. The further increase of the gas injection rate from 12,000 to 18,000 $\mathrm{m}^{3} / \mathrm{d}$ resulted in reaching the operational gas-oil-ratio limit in the production well (Table 3 ), wherein the production ceased. In this case, the recovery factor significantly dropped.

Figure 11 illustrates the cumulative gas production curve versus reservoir average saturation for three different gas injection scenarios (i.e., 8,495, 14158, and $\left.18,122 \mathrm{~m}^{3} / \mathrm{d}\right)$. At the same average gas saturation value, the scenario with an injection rate of $18,122 \mathrm{~m}^{3} / \mathrm{d}$ produced less gas than the scenario with an injection rate of $8,495 \mathrm{~m}^{3} / \mathrm{d}$. Therefore, the former scenario could have a higher recovery factor. In the scenario with an injection rate of $14,158 \mathrm{~m}^{3} / \mathrm{d}$, the injected gas and the released solution gas broke through very soon in the production well, and the production well ceased to produce more hydrocarbon due to the maximum GOR constraint limit.

\subsection{Single-parameter optimization of the $W A G$ flooding scenario}

3.4.1. WAG cycle time optimization

Different WAG ratios introduce various mixture zones and displacement mechanisms in a formation. Varying cycle time obviously changes the number of cycles, which might affect the ultimate recovery of a flooding process. Figure 12 depicts the result of about 1500 simulations during the SA optimization of WAG cycle time with a fix slug size. As is clear, the optimization of more parameters (i.e., water and gas cycle time) sharply increases the number of function calls (i.e., 1500 simulations) during the optimization.

The optimum recovery factor, $43.3 \%$, was obtained at a point with water and gas injection cycle times of 81.5 and 180 days, respectively. A closer look into the available results reveals that some realizations have a better ultimate recovery factor than the other realizations. Figure 12(b) shows this significant trend. These points are some local minimum of the objective function that lies on a straight line, which passes through the origin of this figure. The global minimum at the highest recovery value (i.e., 43.3\%) also lies on this straight line. Considering the water and gas injection rates $\left(238.48 \mathrm{~m}^{3} / \mathrm{d}\right.$ and $18,405 \mathrm{~m}^{3} / \mathrm{d}$, respectively) along with the computed optimum cycle times resulted in the optimum WAG ratio of almost 1:1 (in field unit MSCF/STB).

$$
\begin{aligned}
\text { WAG Ratio }= & \frac{\text { Volume of injected water }}{\text { Volume of injected gas }} \\
& \approx 1.70 \frac{\mathrm{m}^{3}}{\mathrm{~m}^{3}}=1 \frac{S T B}{M S C F} .
\end{aligned}
$$

\subsubsection{Water injection rate optimization in WAG scenario}

The second scenario during the proposed WAG optimization involves the optimization of the water injection rate while keeping the cycle times and gas injection rate from the previous scenario constant. Figure 13 illustrates the function calls during the SA optimization. The behavior of this figure can be divided into three subsections (distinguished by two vertical dashed 


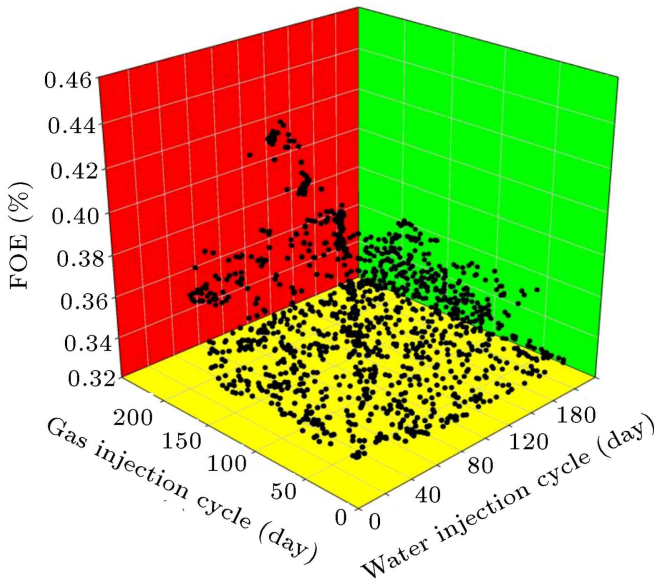

(a)

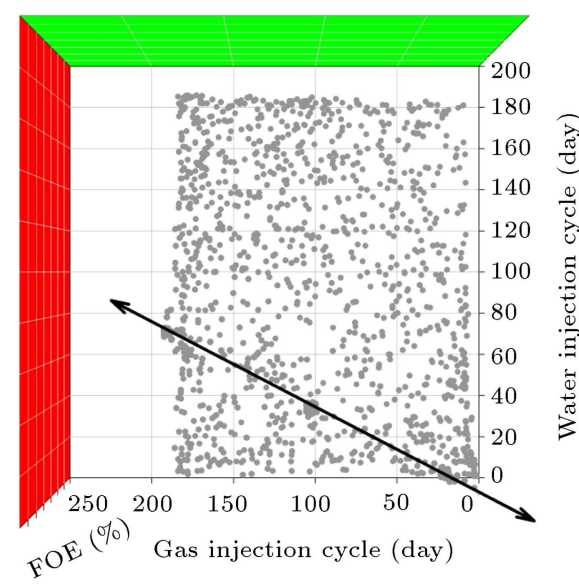

(b)

Figure 12. (a) Recovery factor from 1000 simulations based on different water and gas injection cycles. In each scenario, values of $238.48 \mathrm{~m}^{3} / \mathrm{d}$ and $18,405 \mathrm{~m}^{3} / \mathrm{d}$ were considered for water and gas injection rates, respectively. (b) Top view of (a) showing a trend between gas and water injection cycles with a higher recovery factor.

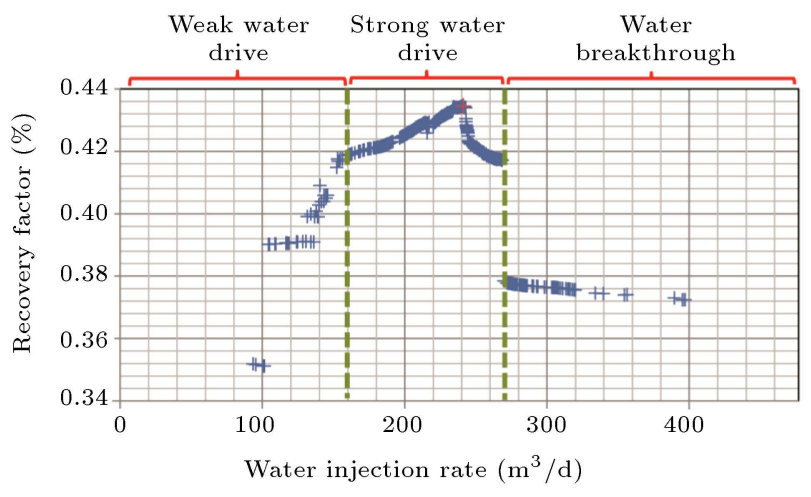

Figure 13. Recovery factor from 560 simulations with different water injection flow rates during WAG flooding. A value of $18,405 \mathrm{~m}^{3} / \mathrm{d}$ and $238.48 \mathrm{~m}^{3} / \mathrm{d}$ was considered for gas injection rate and production, respectively, during all simulations.

lines). Before the injection rate of $160 \mathrm{~m}^{3} / \mathrm{d}$ and due to the insufficient pressure maintenance, the recovery factor was low (i.e., weak water drive mechanism). The optimum injection rate was achieved at a value of $242.6 \mathrm{~m}^{3} / \mathrm{d}$ with a recovery factor of $43.4 \%$. In addition, the recovery factor plummeted by a greater increase in the water rate after $270 \mathrm{~m}^{3} / \mathrm{d}$ due to the quick breakthrough of the water phase in the production well. It is worth noting that the calculated optimum injection rate of $242.6 \mathrm{~m}^{3} / \mathrm{d}$ is very close to the optimum injection rate from the waterflooding scenario (i.e., $238.48 \mathrm{~m}^{3} / \mathrm{d}$ ). In addition, this value is in agreement with the result of the optimum WAG ratio of $1: 1$ from the previous section.

\subsubsection{Gas injection rate optimization in WAG scenario}

In this scenario, an optimum condition for the gas injection rate during the WAG flooding is investigated.

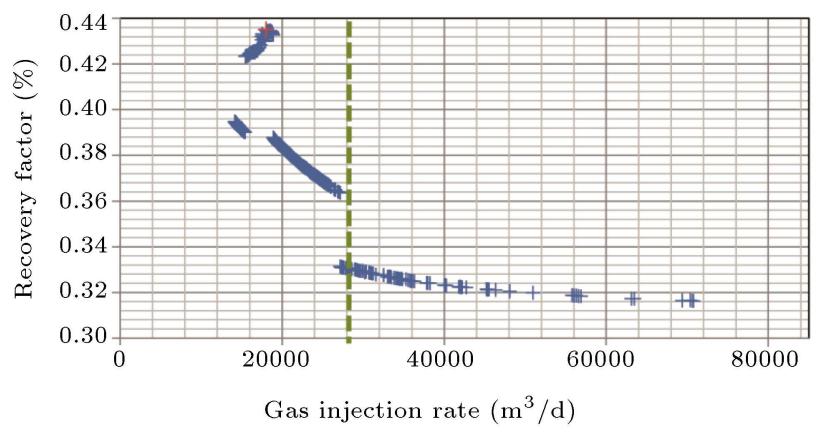

Figure 14. Gas injection rate optimization of WAG flooding scenario (751 simulations). The optimum gas injection rate of $18,859 \mathrm{~m}^{3} / \mathrm{d}$ with the ultimate recovery factor of $43.5 \%$ is shown with a red cross.

During the optimization, the optimized values of the water injection rate and cycle times from the previous analyses were implemented. An optimized gas injection rate of $18,859 \mathrm{~m}^{3} / \mathrm{d}$ was found with a maximum recovery factor of $43.5 \%$ (Figure 14). The interesting point of the computed optimum rate is that this value is again very close to the optimum WAG ratio (i.e., 1:1 in field unit) calculated from the section "WAG cycle time optimization". It indicates that the optimum injection rates of water and gas should be in agreement with the optimum WAG ratio.

\subsubsection{Simultaneous parameter optimization of WAG parameters}

In contrast to the previous sections in which WAG parameters were individually optimized, the aim of this section is to optimize the WAG flooding parameters (i.e., water and gas injection rates and water and gas injection cycles) simultaneously. Since the result of four parameters cannot be depicted in a single figure, water and gas slug sizes (i.e., injection rate $\times$ cycle time) 


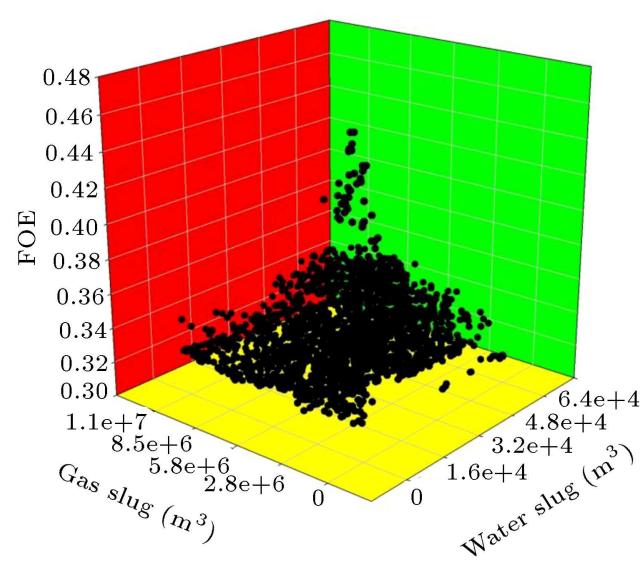

(a)

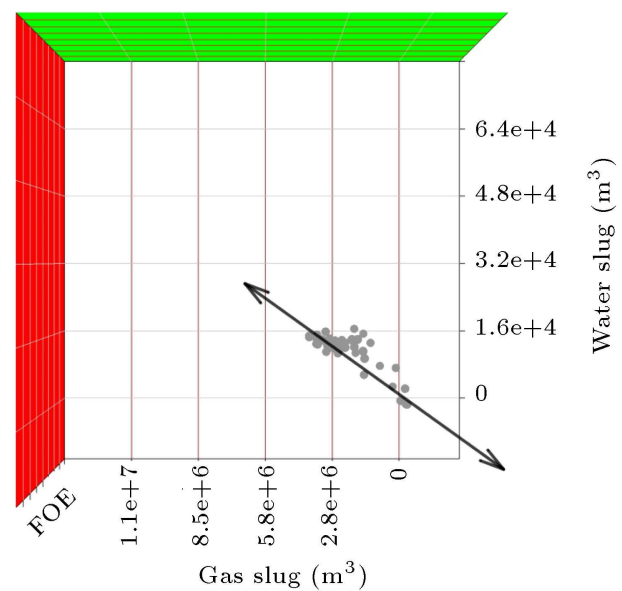

(b)

Figure 15. (a) Recovery factor (FOE) of nearly 2800 reservoir simulations for different water and gas slug sizes. During the optimization, all WAG parameters were considered simultaneously. (b) Top-view of (a) and by only filtering the simulation results with more than $38 \%$ recovery factor. The simulation results lie on a straight line, showing a WAG ratio of $1: 1$.

Table 4. Summary of the optimization results.

\begin{tabular}{|c|c|c|c|c|}
\hline Scenario & Optimization parameter & Optimum parameter & $\begin{array}{c}\text { Recovery } \\
\text { factor }(\%)\end{array}$ & $\begin{array}{l}\text { Incremental } \\
\text { recovery }(\%)^{*}\end{array}$ \\
\hline Natural production & Production rate & $390.63 \mathrm{~m}^{3} / \mathrm{d}$ & 28.9 & - \\
\hline Water flooding & Injection rate & $164.55 \mathrm{~m}^{3} / \mathrm{d}$ & 35.5 & 6.6 \\
\hline Gas injection & Injection rate & $18,122 \mathrm{~m}^{3} / \mathrm{d}$ & 39.1 & 10.2 \\
\hline \multirow{3}{*}{$\begin{array}{l}\text { Individual WAG } \\
\text { parameter optimization }\end{array}$} & Water and gas cycle time & 81.5 days, 180 days & 43.3 & 14.4 \\
\hline & Water injection Rate & $242.61 \mathrm{~m}^{3} / \mathrm{d}$ & 43.4 & 14.5 \\
\hline & Gas injection rate & $18,859 \mathrm{~m}^{3} / \mathrm{d}$ & 43.5 & 14.6 \\
\hline $\begin{array}{c}\text { Simultaneous } \\
\text { parameter optimization }\end{array}$ & $\begin{array}{l}\text { Water injection rate, } \\
\text { Water cycle, } \\
\text { Gas injection rate, } \\
\text { Gas cycle }\end{array}$ & $\begin{array}{l}88.23 \mathrm{~m}^{3} / \mathrm{d}, \\
181 \text { days, } \\
26,023 \mathrm{~m}^{3} / \mathrm{d}, \\
110 \text { days }\end{array}$ & 46 & 17.1 \\
\hline
\end{tabular}

* Incremental recovery with respect to the primary production.

were used to show all simulation results in a $3 \mathrm{D}$ graph (see Figure 15(a)). The optimum scenario resulted in a recovery factor of $46 \%$ for the water injection rate and cycle time of $88.24 \mathrm{~m}^{3} / \mathrm{d}$ and 181 days, respectively, and the gas injection rate and cycle time of $26,023 \mathrm{~m}^{3} / \mathrm{d}$ and 110 days, respectively. The first interesting issue with the computed results is that the simultaneous optimization of the WAG parameters results in the ultimate recovery factor that is almost $3 \%$ higher than that in the individual optimization results. Second, in compliance with our previous results, the optimum WAG ratio in this optimization scenario is again 1:1 (in field unit). This behavior is well illustrated in Figure 15(b), in which the top view of Figure 15(a) is shown for those simulation points with a higher recovery factor (e.g., $>38 \%$ ). All simulation results lie on a straight line, showing a WAG ratio of $1: 1$. This shows that, during WAG optimization, WAG ratio can be an important parameter and will remain almost constant irrespective of the manner of optimizations.

\subsection{Summary}

Table 4 summarizes the optimization results of all scenarios. Recovery factor increases from waterflooding to gas injection and rises even more during WAG flooding. As is shown, the simultaneous optimization of all parameters has the highest ultimate recovery factor.

Figure 16 depicts the average reservoir pressure during all optimum-flooding scenarios. As can be seen, subsequent to the natural production period, all scenar- 


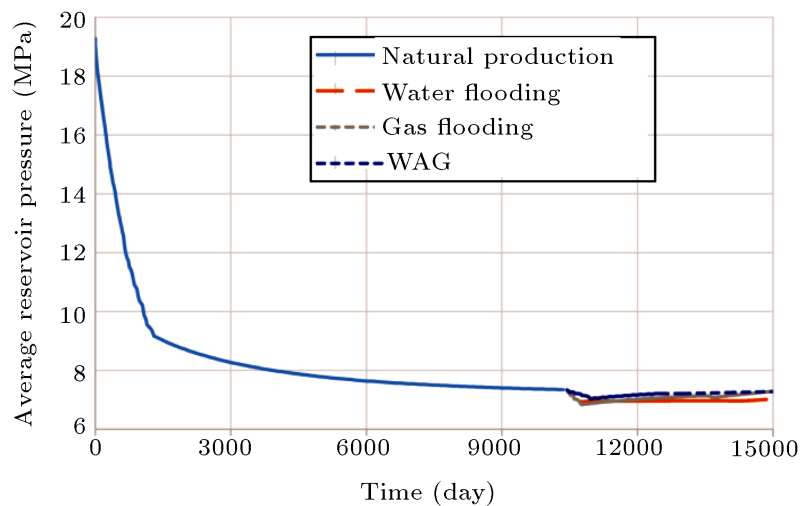

Figure 16. Average reservoir pressure for different optimized scenarios, including natural production (with the rate of $390.63 \mathrm{~m}^{3} / \mathrm{d}$ ), water flooding (with an flooding rate of $164.55 \mathrm{~m}^{3} / \mathrm{d}$ ), gas flooding (with an injection rate of $18,122 \mathrm{~m}^{3} / \mathrm{d}$ ), and WAG flooding (simultaneous optimization of all parameters) showing pressure maintenance of the reservoir during all flooding scenarios.

ios result in nearly constant reservoir pressure maintenance in the formation. In other words, the flooding process could maintain the reservoir pressure after the natural production period with a constant trend.

\section{Conclusion}

In this study, a simulated annealing optimizer was coupled with a reservoir simulator to investigate the efficiency of different production-injection scenarios. The recovery factor was selected as an objective function. The considered scenarios include optimization of natural production, waterflooding, gas injection, individual WAG parameters, and simultaneous WAG parameters. The developed model was then applied to a case study from an Iranian offshore formation. The role of different operational constraints including production mode change (i.e., from constant rate to constant BHP), closing perforations above a maximum water-cut, or GOR limit was analyzed. The obtained results indicate that:

(a) The operational constraints could considerably alter the production characteristics of a flooding scenario by changing the production mechanism (e.g., from solution-gas-drive to secondary-gascap-drive). Therefore, these production restrictions could alter the final optimal scenario and should always be analyzed;

(b) The recovery factor of the optimized WAG scenario $(46 \%)$ was clearly higher than that of the optimized natural production $(28.9 \%)$, waterflooding $(35.5 \%)$, and gas injection $(39.1 \%)$;

(c) The ultimate recovery factor of the individual WAG parameter optimization (in average $43.4 \%$ ) was certainly less than the simultaneous optimization of all parameters $(46 \%)$. This reveals that to find the best scenario during simulation optimization, all parameters should be optimized together;

(d) Irrespective of the number of variables during optimizations, the WAG ratio (i.e., the volume fraction of injected water to gas) remains almost constant and equal to $1: 1$ in the field unit.

The obtained results can facilitate:

(a) Finding the role of operational constraints during optimization of primary production, secondary recovery, and WAG flooding scenarios;

(b) The manner of optimization of influential parameters during flooding scenarios.

However, during a production-optimization process, many uncertain parameters are available where a scenario-based model cannot completely address them. These uncertainties cause non-uniqueness of solutions that should be obtained with a probabilistic method without overly exhausting simulation resources [56]. Thus, future studies are required to reveal the effect of different uncertain inputs on the result of simulationoptimizations. One possible approach could be finding the effect of these uncertainties through the implementation of the Monte Carlo simulations during simulation optimizations. Finding a proper optimization algorithm that can handle the non-linearity of complex hydrocarbon formations and reduce the computation time is worthy of research. Furthermore, in this study, only the role of operational parameters was considered during the task of finding the success of the WAG flooding project, while the effect of reservoir parameters (e.g., heterogeneity, petrophysical properties, and fluid properties) [36] is open for further investigations. Finally, in this study, a rather simple objective function (i.e., recovery factor) was studied. The implementation of more complicated objective functions (e.g., net present value) and multiple-objective functions can be the title of future research.

\section{References}

1. Tamsilian, Y. and Ramazani, S. "Enhanced oil recovery performance and time-dependent role of polymeric core-shell nanoemulsion", Sci. Iran, 21(3), p. 1174 (2014).

2. Ashrafizadeh, M., Ramazani S.A., A., and Sadeghnejad, S. "Enhanced polymer flooding using a novel nano-scale smart polymer: Experimental investigation", Can. J. Chem. Eng., 95(11), pp. 2168-2175 (2017).

3. Golshokooh, S., Ramazani S.A., A., and Hekmatzadeh, M. "Investigating the effect of hybrid silica 
nanoparticles-copolymer on increasing oil recovery in a three dimensional porous media", Sci. Iran, 24(6), pp. 3466-3475 (2017).

4. Ashrafizadeh, M., Ahmad, R.S., and Sadeghnejad, S. "Improvement of polymer flooding using in-situ releasing of smart nano-scale coated polymer particles in porous media", Energ. Explor. Exploit, 30(6), pp. 915-939 (2012).

5. Farasat, A., Sefti, M.V., Sadeghnejad, S., et al. "Mechanical entrapment analysis of enhanced preformed particle gels (PPGs) in mature reservoirs", J. Petrol. Sci. Eng., 157, pp. 441-450 (2017).

6. Kessel, D. "Chemical flooding-status report", J. Petrol. Sci. Eng., 2(2-3), pp. 81-101 (1989).

7. Moradi, B., Pourafshary, P., Jalali, F., et al. "Experimental study of water-based nanofluid alternating gas injection as a novel enhanced oil-recovery method in oil-wet carbonate reservoirs", J. Natural Gas Sci. Eng., 27, pp. 64-73 (2015).

8. Kharrat, R., Mahdavi, S., and Ghorbani, D. "A comprehensive EOR study of a highly fractured matured field-case study", SPE Europec/EAGE Annual Conference (2012).

9. Christensen, J.R., Stenby, E.H., and Skauge, A. "Review of WAG field experience", International Petroleum Conference and Exhibition of Mexico, (1998).

10. Gao, Y., Zhao, M., Wang, J., et al. "Performance and gas breakthrough during $\mathrm{CO}_{2}$ immiscible flooding in ultra-low permeability reservoirs", Petrol. Explor. Dev., 41(1), pp. 88-95 (2014).

11. Kamali, F., Hussain, F., and Cinar, Y. "An experimental and numerical analysis of water-alternatinggas and simultaneous-water-and-gas displacements for carbon dioxide enhanced oil recovery and storage", SPE Journal, 22(02), pp. 521-538 (2016).

12. Kamali, F. and Cinar, Y. "Co-optimizing enhanced oil recovery and $\mathrm{CO}_{2}$ storage by simultaneous water and $\mathrm{CO}_{2}$ injection", Energ. Explor. Exploit, 32(2), pp. 281300 (2014).

13. Feng, W., Deping, Z., Guojun, Y., et al. "CO flooding WAG safety control technology", SPE Asia Pacific Oil and Gas Conference and Exhibition (2013).

14. Brown, J., Al-Kobaisi, M., and Kazemi, H. "Compositional phase trapping in $\mathrm{CO}_{2}$ WAG simulation", Paper SPE 165983 presented at the SPE Reservoir Characterization and Simulation Conference and Exhibition, Abu Dhabi, UAE, September (2013).

15. Yan, Y., Li, C., Dong, Z., et al. "Enhanced oil recovery mechanism of $\mathrm{CO}_{2}$ water-alternating-gas injection in silica nanochannel", Fuel, 190, pp. 253-259 (2017).

16. Liu, P. and Zhang, X. "Enhanced oil recovery by $\mathrm{CO}_{2} \mathrm{CH}_{4}$ flooding in low permeability and rhythmic hydrocarbon reservoir", International Journal of Hydrogen Energy, 40(12849), p. e12853 (2015).
17. Wen, T., Thiele, M.R., Ciaurri, D.E., et al. "Waterflood management using two-stage optimization with streamline simulation", Comp. Geosci, 18(3-4), pp. 483-504 (2014).

18. Eshraghi, S.E., Rasaei, M.R., and Zendehboudi, $\mathrm{S}$. "Optimization of miscible $\mathrm{CO}_{2}$ EOR and storage using heuristic methods combined with capacitance/resistance and Gentil fractional flow models", $J$. Natural Gas Sci. Eng., 32, pp. 304-318 (2016).

19. Javaheri, P. and Sadeghnejad, S., "Effect of injection pattern arrangements on formation connectivity during water flooding", SPE Europec Featured at 79th EAGE Conference and Exhibition (2017).

20. Farasat, A., Sefti, M.V., Sadeghnejad, S., et al. "Effects of reservoir temperature and water salinity on the swelling ratio performance of enhanced preformed particle gels", Kor. J. Chem. Eng., 34(5), pp. 15091516 (2017).

21. Hallam, R.J., Ma, T.D., and Reinbold, E.W. "Performance evaluation and optimization of the Kuparuk hydrocarbon miscible water-alternating-gas flood", Geological Society, London, Special Publications, 84(1), pp. 153-164 (1995).

22. Bedrikovetsky, P., Andrade, G.M., Ferreira, L.E.A. et al. "Optimization of tertiary water-alternate- $\mathrm{CO}_{2}$ injection", in SPE Latin America/Caribbean Petroleum Engineering Conference, Society of Petroleum Engineers: Port-of-Spain, Trinidad (1996).

23. Guo, X., Du, Z., Sun, L., et al., "Optimization of tertiary water-alternate- $\mathrm{CO}_{2}$ flood in Jilin oil field of China: Laboratory and simulation studies", SPE/DOE Symposium on Improved Oil Recovery (2006).

24. Ghomian, Y., Pope, G.A., and Sepehrnoori, K. "Hysteresis and field-scale optimization of WAG injection for coupled $\mathrm{CO}_{2}$-EOR and sequestration", SPE Symposium on Improved Oil Recovery (2008).

25. Alizadeh, M., Moshirfarahi, M.M., and Rasaie, M.R. "Mathematical and neural network prediction model of three-phase immiscible recovery process in porous media", J. Natural Gas Sci. Eng., 20, pp. 292-311 (2014).

26. Liu, P., Zhang, X., Hao, M., et al., "Parameter optimization of gas alternative water for $\mathrm{CO}_{2}$ flooding in low permeability hydrocarbon reservoirs", Journal of Renewable and Sustainable Energy, 8(3), p. 035901 (2016).

27. Chen, Y., He, L., Guan, Y., et al., "Life cycle assessment of greenhouse gas emissions and water-energy optimization for shale gas supply chain planning based on multi-level approach: Case study in Barnett, Marcellus, Fayetteville, and Haynesville shales", Energy Convers. Manag, 134, pp. 382-398 (2017).

28. Chen, Y., He, L., Li, J., et al., "Multi-criteria design of shale-gas-water supply chains and production systems towards optimal life cycle economics and greenhouse gas emissions under uncertainty", Comput, Chem. Eng., 109, pp. 216-235 (2018). 
29. Garcia Quijada, M., Optimization of a $\mathrm{CO}_{2}$ Flood Design Wesson Field-West Texas, Texas A\&M University (2006).

30. Yang, D., Zhang, Q., and Gu, Y. "Integrated optimization and control of the production-injection operation systems for hydrocarbon reservoirs", J. Petrol. Sci. Eng., 37(1), pp. 69-81 (2003).

31. Gharbi, R. "Application of an expert system to optimize reservoir performance", Journal of Petroleum Science and Engineering, 49(3), pp. 261-273 (2005).

32. Esmaiel, T.E. and Heeremans, J.C. "Optimization of the WAG process under uncertainty in a smart wells environment: Utility theory approach", Intelligent Energy Conference and Exhibition (2006).

33. Ma, J., Design of an Effective Water-alternatinggas (WAG) Injection Process Using Artificial Expert Systems, The Pennsylvania State University (2010).

34. Odi, U. and Gupta, A. "Optimization and design of carbon dioxide flooding", Abu Dhabi International Petroleum Exhibition and Conference (2010).

35. Rahmawati, S.D., Whitson, C.H., and Foss, B. "A mixed-integer non-linear problem formulation for miscible WAG injection", Journal of Petroleum Science and Engineering, 109, pp. 164-176 (2013).

36. Mohagheghian, E., An Application of Evolutionary Algorithms for WAG Optimisation in the Norne Field, Memorial University of Newfoundland (2016).

37. Haupt, R.L. and Haupt, S.E., Practical Genetic Algorithms, John Wiley \& Sons (2004).

38. Dréo, J., Petrowski, A., Siarry, P. et al., Metaheuristics for Hard Optimization: Methods and Case Studies, Springer Science \& Business Media (2006).

39. Soltani, A. and Sadeghnejad, S. "Scaling and critical behavior of lattice and continuum porous media with different connectivity configurations", Physica A: Statistical Mechanics and Its Applications, 508, pp. 376389 (2018).

40. Sadeghnejad, S. and Masihi, M. "Analysis of a more realistic well representation during secondary recovery in 3-D continuum models", Comp. Geosci, 21(5-6), pp. 1035-1048 (2017).

41. Sadeghnejad, S., Masihi, M., King, P., et al. "Study the effect of connectivity between two wells on secondary recovery efficiency using percolation approach", $E C$ MOR XV-15th European Conference on the Mathematics of Oil Recovery (2016).

42. Sadeghnejad, S. and Masihi, M. "Point to point continuum percolation in two dimensions", J. Stat. Mech. 2016 (10), p. 103210 (2016).

43. Sadeghnejad, S., Masihi, M., Pishvaie, M., et al. "Rock type connectivity estimation using percolation theory", Math. Geosci, 45(3), pp. 321-340 (2013).

44. Sadeghnejad, S., Masihi, M., and King, P. "Dependency of percolation critical exponents on the exponent of power law size distribution", Phys. A., 392(24), pp. 6189-6197 (2013).
45. Parashar, M. and Hariri, S., Autonomic Computing: Concepts, Infrastructure, and Applications, CRC press (2006).

46. Hemmati-Sarapardeh, A., Mohagheghian, E., Fathinasab, M., et al. "Determination of minimum miscibility pressure in N2-crude oil system: A robust compositional model", Fuel, 182, pp. 402-410 (2016).

47. Kwak, T.-S., Jung, J.-H., Han, D.-K., et al. "Development of well placement optimization model using artificial neural network and simulated annealing", $J$. Korean Inst. Gas., 19(1), pp. 28-37 (2015).

48. Khoshneshin, R. and Sadeghnejad, S. "Integrated well placement and completion optimization using heuristic algorithms: A case study of an Iranian carbonate formation", J. Chem. Petrol. Eng., 52(1), pp. 35-47 (2018).

49. Montazeri, M. and Sadeghnejad, S. "An investigation of optimum miscible gas flooding scenario: A case study of an Iranian carbonates formation", Iran. J. Oil Gas Sci.Tech., 6(3), pp. 41-54 (2017).

50. Kirkpatrick, S., Gelett, C., and Vecchi, M. "Opimization by simulated annealing", Sci., 220, p. 671 (1983).

51. Černý, V. "Thermodynamical approach to the traveling salesman problem: An efficient simulation algorithm", J. Opt., Theo. App., 45(1), pp. 41-51 (1985).

52. Spall, J.C., Introduction to Stochastic Search and Optimization: Estimation, Simulation, and Control, 65, John Wiley \& Sons (2005).

53. Spiteri, E.J. and Juanes, R. "Impact of relative permeability hysteresis on the numerical simulation of WAG injection", J. Petrol. Sci. Eng., 50(2), pp. 115-139 (2006).

54. Aziz, K. and Settari, A., Petroleum Reservoir Simulation, 2nd Edn., Blitzorint Ltd., Canada, p. 476 (2002).

55. Terry, R.E. and Rogers, J.B., Applied Petroleum Reservoir Engineering, Pearson Education (2013).

56. Wantawin, M., Yu, W., and Sepehrnoori, K. "An iterative work flow for history matching by use of design of experiment, response-surface methodology, and Markov chain Monte Carlo algorithm applied to tight oil reservoirs", SPE, 20(03), pp. 613-626 (2017).

\section{Appendix A}

\section{A.1. Simulated annealing strategy}

Simulated Annealing (SA) is a probabilistic technique that was originally inspired by the process of metal annealing in metallurgy. This method attempt to model the controlled heating and cooling process of a material in order to change its physical properties (e.g., increasing the size of its crystals) by altering its internal structure (i.e., minimizing its thermodynamic free energy).

Figure A.1 depicts the optimization procedure of SA. The algorithms start with setting the initial temperature and generating a random solution. Next, 


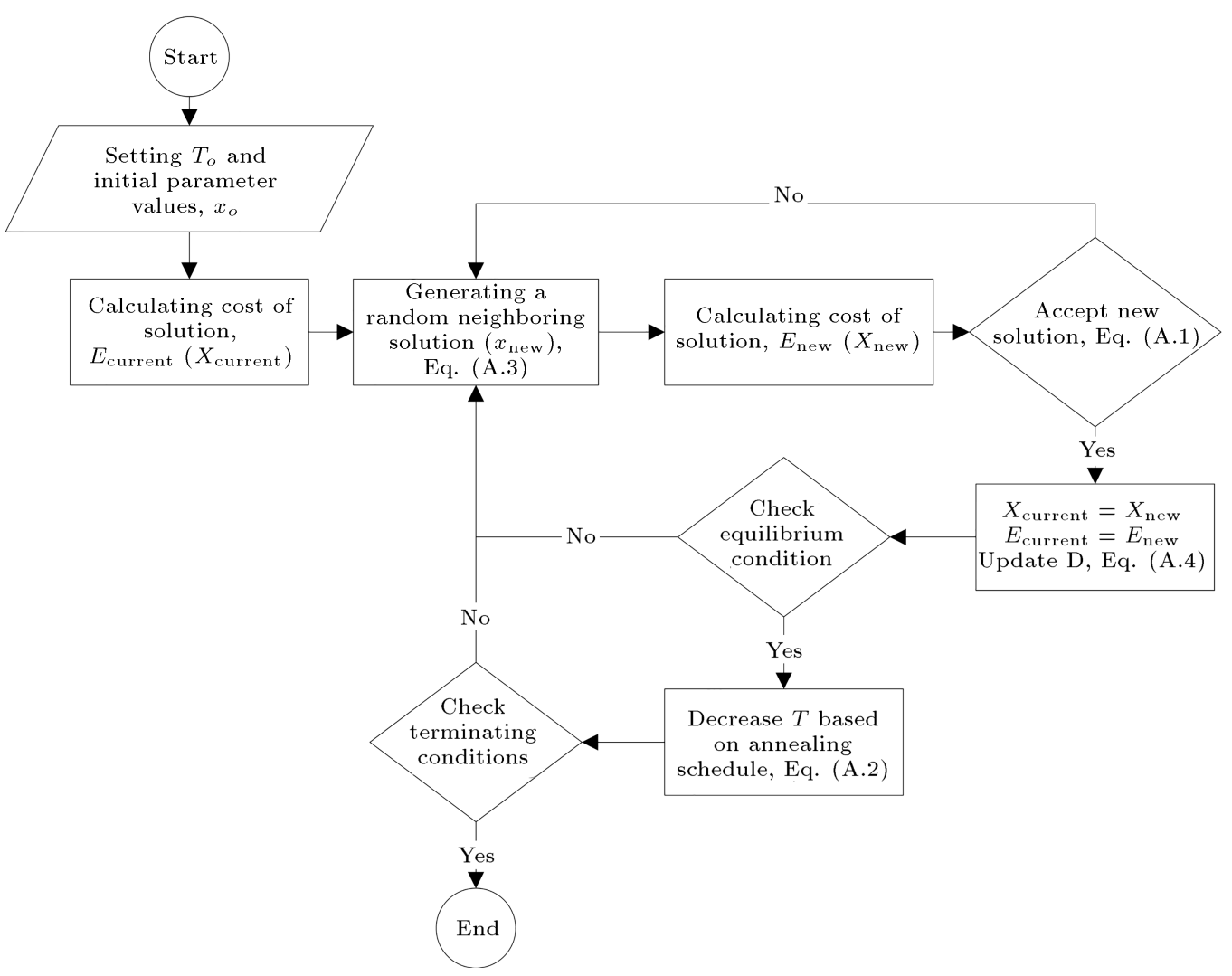

Figure A.1. Flow chart of the simulation annealing procedure.

the objective function value is evaluated for the random solution. Subsequently, a random neighboring solution should be generated by making a small change to the current solution. The new solution's cost is calculated, and a decision will be made whether to move this solution (i.e., new state) based on an acceptance probability function. This procedure continues reaching the equilibrium condition (i.e., in practice, repeating the process for a large value). Then, the system temperature is decreased based on an annealing schedule temperature, and the previous steps are repeated until the stop condition (termination condition) is met.

\section{A.2. Annealing temperature}

SA incorporates a temperature parameter, $T$, into the minimization procedure. $T$ is initially set high $\left(T_{0}\right)$ and, then, is allowed to slowly 'cool' as the algorithm runs. At high temperatures, the algorithm will be allowed to accept worse solutions, which often guarantee to avoid being trapped in local optimums. Thus, accepting worse solutions allows the algorithm to extensively search for optimal solutions. As the temperature declines, the chance of accepting worse solutions reduces; therefore, the algorithm focuses on search spaces that may contain final optimum solutions. Moreover, in each fixed number of steps, the annealing parameters are set to lower values than that of iteration number (i.e., $T$ increases). This process is called restarting or re-annealing that again helps the algorithm to escape local solutions. In our case, we run the re-annealing module every 130th iteration. This parameter was tuned by trying a couple of simulation-optimization runs.

\section{A.3. Acceptance probability}

An acceptance distribution probability $(p)$ is defined, which depends on the difference between the new cost function value, $E_{\text {new }}$, and the current saved cost value, $E_{\text {current }}$, and also the system temperature, $T$. In our methodology, achieving the maximum ultimate recovery is defined as a cost function ( $E=$ recovery factor). The acceptance probability, $p$, decides probabilistically whether to stay in the current state or to bounce out of it. In our model, if the new state (i.e., the new recovery factor) is better than the current state, it becomes the next solution, while if the new state is worse than the current state (i.e., the new recovery factor is lower than the current recovery factor), the algorithm can still consider it as the next point with the acceptance probability of:

$$
p=\frac{1}{1+\exp \left(\frac{\Delta E}{T}\right)},
$$

where $\Delta E=E_{\text {new }}-E_{\text {current }}$. The acceptance probability is between 0 and $1 / 2$. Lower temperature results in 
lower acceptance probability, and vice versa. Moreover, larger $\Delta E$ leads to lower $p$.

\section{A.4. Annealing schedule}

Carefully controlling the rate of cooling of the temperature can guarantee to reach more optimum conditions. The cooling rate should be low enough for the probability distribution of the current state to be close to the thermodynamic equilibrium. The algorithm systematically lowers $T$ and stores the best state found so far. In our algorithm, the cooling rate follows the following equation:

$$
T=T_{0} \times 0.95^{k}
$$

where $T_{0}$ is the initial temperature of the system, and $k$ is the same as the iteration number until re-annealing. For better optimization purposes, $T_{0}$ is selected in such a way that the algorithm is able to explore the entire search space better before any cooling. The value of $T_{0}$ clearly depends on the scaling of $\Delta E$ and, thus, is problem-specific. To determine $T_{0}$ in our optimization, an $80 \%$ acceptance chance is considered for a change that increases the objective function at initial temperatures. By conducting an initial search of our simulation-optimization approach, $T_{0}$ of $150 \mathrm{~K}$ is selected based on the specified criteria.

\section{A.5. Generating neighboring solution}

During the optimization, the new solutions, $x_{\text {new }}$, are generated from the current solution, $x_{\text {current }}$, according to the formula:

$$
x_{\text {new }}=x_{\text {current }}+D \times R,
$$

where $x$ is the vector of variables. During our production-injection scenario, parameters such as production rate, water/gas injection rates, or cycle times were considered as our decision variables. $R \in[-1,+1]$ is a vector of random numbers and $D$ is a diagonal matrix, which defines the maximum allowable changes in each variable. $D$ is updated after an acceptable change in the state of the solution as follows:

$$
D_{\text {new }}=(1-\beta) D_{\text {current }}+\beta D_{\text {success }} .
$$

$\beta$ is the weighting factor ( 0.85 was considered in our algorithm), and $D_{\text {success }}$ consists of the magnitude of the changes in each control variable in the new successful state. This equation controls the maximum step size associated with each control variable.

\section{A.6. Terminating condition}

The final $T$ in our algorithm was determined when the system sufficiently cooled or the search ceased making progress. In other words, it is either no improvement being found at each temperature or the acceptance ratio falling below a small value (i.e., $10^{-6}$ in our algorithm).

\section{Biographies}

Saeid Sadeghnejad is an Assistant Professor of Petroleum Engineering, Tarbiat Modares University, Iran. His research interests include formation characterization using pore-scale methods and EOR. He holds a BS degree in Chemical Engineering, and MS and $\mathrm{PhD}$ degrees in Petroleum Engineering from Sharif University of Technology, Iran.

Mehrdad Manteghian is a Professor of Chemical Engineering, Tarbiat Modares University, Iran. His research interests include industrial crystallization and mass transfer. He holds a BS degree in chemical Engineering from AmirKabir University and MS and $\mathrm{PhD}$ degrees in Chemical Engineering from UMIST University, UK.

Hossein Rouzsaz obtained his MSc degree in Petroleum Engineering from Tarbiat Modares University, Tehran, Iran. His study area is EOR. Mr. Rouzsaz holds a BS degree in Petroleum Engineering, from Petroleum University of Technology, Iran. 